\begin{tabular}{|c|c|c|}
\hline \multirow[t]{2}{*}{7} & $\begin{array}{l}\text { International Journal of Current Research in } \\
\text { Biosciences and Plant Biology }\end{array}$ & \\
\hline & Volume $4 \bullet$ Number 4 (April-2017) • ISSN: 2349-8080 (Online) & \\
\hline $\begin{array}{l}\text { EXUELLEN } 1 \\
\text { PUBLISHERS }\end{array}$ & Journal homepage: www.ijcrbp.com & \\
\hline
\end{tabular}

\title{
The Identification Method for Machilus Nees Species Based on Visible-Near Infrared Spectral Analysis Technology
}

\author{
Yue Fei, Bo Xiao, Xianbin Liao, Sitao Wen, Biyu Zhou, Jiayao Pan and Die Hu*
}

Germplasm Resources Evaluation and Innovation Center of Phoebe Yangtze University, Hubei, Jingzhou, People's Republic of China

*Corresponding author.

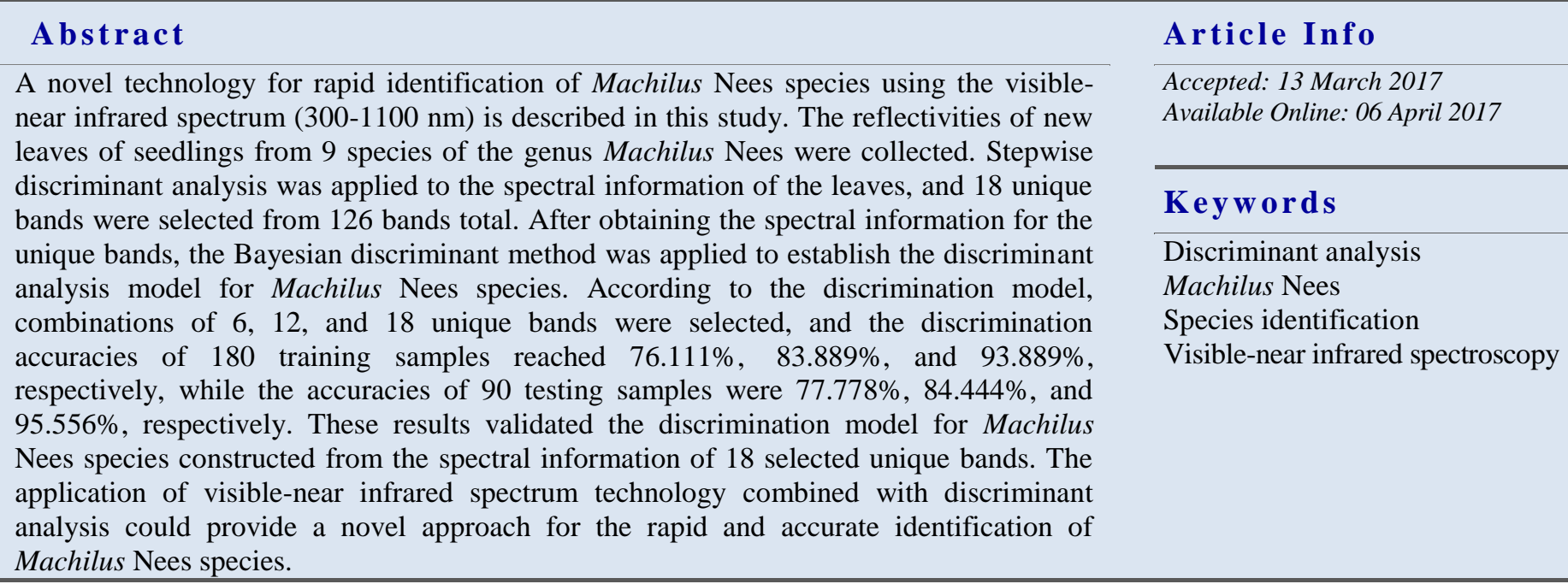

\section{Introduction}

There are about 100 species in the genus Machilus Nees of the family Lauraceae with diverse varieties and worldwide distribution. There are 84 species and 4 varieties in China with 66 endemic species ( $\mathrm{Li}$ et al., 2008), and most are phenetic species of tropical and subtropical forests (Lin, 2007). This genus of plants not only has great potential in gardens, buildings, and spice (Liu and Fei, 2011), but also plays important roles in the common economic forest in southern China. Therefore, they are of great interest to botanists.
However, due to their close genetic relationship and external morphology, especially the extremely similar leaf shape, plants in Machilus Nees are difficult to discriminate, and incorrect identifications occur easily. The traditional identification methods for Machilus Nees plants mainly include morphology (Zhong and Xia, 2010), leaf epidermis anatomy, palynology (Wang and Wei, 2003; Wei and Tang, 2006), and molecular systematics (Chen et al., 2009). Previously, traditional classification methods, the classic macro-morphology identification method based on flower and fruit characteristics, were the most utilized (Tang and Xiang, 
1995). However, the most easily available organ of Machilus Nees plants, which are evergreen, is the leaf. In addition, due to the short flowering and fruiting seasons as well as significant biennial bearing, the flowers and fruits of Machilus Nees plants are difficult to collect increasing the difficulties of identification and classification for these plants.

Plants can reflect, absorb, and transmit electromagnetic waves. Because of the differences in nutrients, moisture ( $\mathrm{Li}$ and Song, 2016), and chlorophyll (Song et al., 2008) in the leaves among plants, different plants have different absorption, reflection, and radiation characteristics of electromagnetic waves with different wavelengths, i.e., the differences in chemical components and organizational structure among plants can be represented through spectral data (Lin, 2011).

Recently, hyperspectral technology, which was developed from spectroscopy, having the characteristics of high distinguishability and large information content, may resolve the problem of plants with very similar morphological characteristics not being easy to recognize. For example, Pontius et al. (2005) used this hyperspectral technology to compare a mixed deciduous and coniferous forest as well as a pure forest near Harvard in America; classification processing was conducted, with the classification accuracy reaching $75 \%$. Through the analysis of hyperspectral data during the rice growing period, Zhang et al. (2002) designed a hybrid decision tree classification algorithm for which the total classification accuracy of the test samples in the classification experiment reached $94.9 \%$.

For wood identification, Zhuang et al. (2014) used the infrared spectrum to identify the four kinds of woods in the genera of Machilus and Machilus Nees; the two genera could be identified in the spectral regions of $1730-1740 \mathrm{~cm}^{-1}$ and $1640-1650 \mathrm{~cm}^{-1}$. Through the comparison of extracted and treated wood flour, as well as the infrared spectral changes among the five sandalwood species, Zhang et al. (2014) demonstrated that the infrared spectroscopic technique could be used for the identification of wood species.

To sum up, using hyperspectral technology and the corresponding analytical methods to identify stable and effective spectral characteristics of the leaves of Machilus Nees plants could be powerful tools for Machilus Nees species identification.

\section{Materials and methods}

\section{Instruments and software}

The AvaField-1 Portable Hyperspectral Spectrometer (Dutch Avantes Company) with spectral region of 300$1100 \mathrm{~nm}$ and spectrum sampling interval of $0.6 \mathrm{~nm}$ was used in this experiment. Additional equipment included a blade clip, an optical fiber patch cord for field use, a reflective probe with built-in light resource, a reference white board, and computers. During the spectral determination measurements, correction with a standard white board was conducted after each measurement.

AvaField, AvaReader, and SPSS19 multivariate statistical software were used to process the data.

\section{Sample treatment}

Nine species of the genus Machilus Nees cultivated in the bonsai garden of College of Horticulture and Landscape Architecture on the west campus of Yangtze University, Hubei Province were selected, including Machilus multinervia Liou (A), Machilus suaveolens S.Lee (B), Machilus kwangtungensis Yang (C), Machilus decursinervis Chun $\quad$ (D), Machilus oculodracontis Chun (E), Machilus litseifolia S. Lee (F), Machilus pyramidalis $\mathrm{H} . \quad$ W. Li (G), Machilus microcarpa Hemsl. (H), and Machilus longipedicellata Lec. (I). The above species were planted in fifteen centimeter plastic pots on March $18^{\text {th }}, 2016$, and placed on the open ground under shade. On September $9^{\text {th }} 2016$, the second new leaf from the stem tip was collected; a total of 30 leaves were sampled. Twenty training samples and 10 test samples were randomly selected. All samples were stored in valve bags at low temperature with moisture and kept in the dark. Samples were used for the spectrum data collection in the laboratory.

\section{Spectrum data collection}

Before data collection, blade surfaces were cleaned to prevent dust on the blades from impacting the measurements. Then, the instrument was connected and adjusted, leaves were placed face up on the reference white board, the probe was pointed at the blade for determination, and the data were read from AvaField on the computer and stored.

Due to interference from ambient illumination, granularity, density, and surface texture in the 
environment during the measurements, the original spectral curve would have baseline drift (Chen et al., 2016) and noise. Therefore, the data from below $500 \mathrm{~nm}$ and over $1000 \mathrm{~nm}$ with high noise were removed, and the readings between $500 \mathrm{~nm}$ and $1000 \mathrm{~nm}$ with more recognizable spectral signatures were extracted.

\section{Results and discussion}

\section{The analysis of the original spectral reflectivity}

Fig. 1 shows the curves for the average value of spectral reflectivities in the 9 species (in this figure, A, B, C, D, $\mathrm{E}, \mathrm{F}, \mathrm{G}, \mathrm{H}$, and I represent the 9 species of the genus Machilus Nees identified above; the abscissa represents the 126 bands between $500 \mathrm{~nm}$ and $1000 \mathrm{~nm}$; hereafter, each band represents a corresponding characteristic).
This figure reveals that the spectral reflectivities of the 9 Machilus Nees species have significant differences among the bands. Near the bands of $544 \mathrm{~nm}$ and 908 $\mathrm{nm}$, the differences of spectral reflectivities among 9 species were more significant. When the spectral regions were below $500 \mathrm{~nm}$ and above $1000 \mathrm{~nm}$, the reflectivities of the different species had very small differences, and they even crossed or overlapped. Owing to the jumbled information content of the original spectrum, it contained useful information for distinguishing the samples from the other species as well as some irrelevant information. The irrelevant information, including electrical noise, sample background, and stray light, could not be used as effective information for distinguishing species, which would directly negatively impact the modeling precision unless it was excluded.

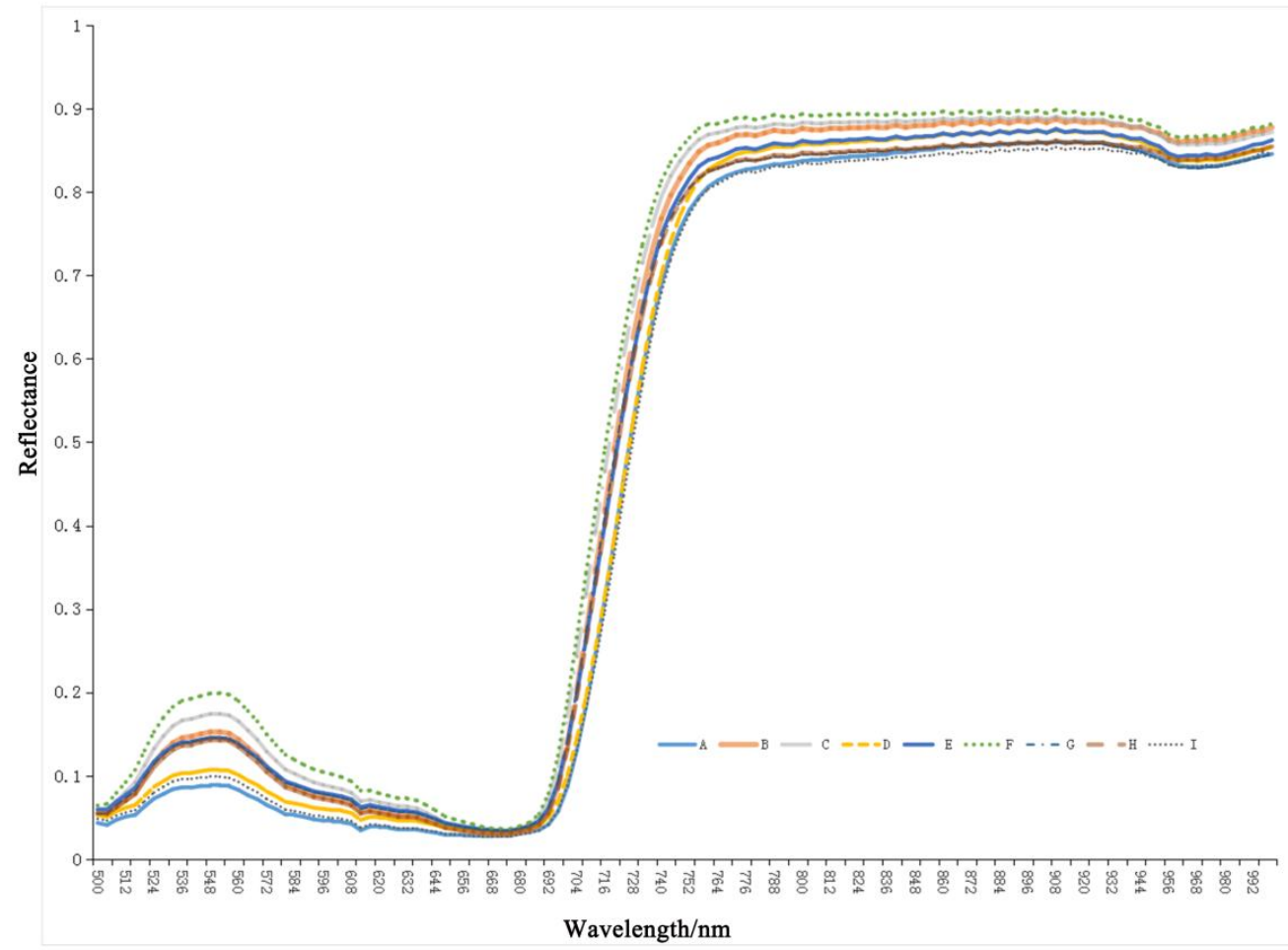

Fig.1: Mean spectral reflectance curve of nine species of Machilus Nees.

\section{The selection of unique bands and the discriminant analysis}

AvaReader software was utilized for the analysis of the obtained spectrum data. One band was selected every 4 $\mathrm{nm}$ for a total of 126 bands, which were equivalent to 126 variables. Each variable had a different function in the recognition of Machilus Nees species. If all the data were used for establishing the discrimination function, large computational resources are needed. In addition, because of the autocorrelation which might have existed between variables, the discrimination function lacked stability, and the model error increased. Therefore, it was necessary to conduct band selection.

The stepwise discriminant analysis method using multivariate statistical software was used; unique bands were screened and selected through introducing and 
removing $\mathrm{F}$ limit. The Bayesian discriminant method was applied to the spectral information of the unique bands to establish the discrimination function, and then the different species of the genus Machilus Nees were distinguished. The spectral information of 18 selected unique bands was used to conduct the discriminant analysis for the 9 Machilus Nees species and establish the linear discriminant model presented in Table 1. Based on the established discrimination function, validation with 180 training samples involved in modeling and prediction of 90 test samples, which were not involved in modeling, were conducted.

Table 1. Stepwise discriminate function of the nine species.

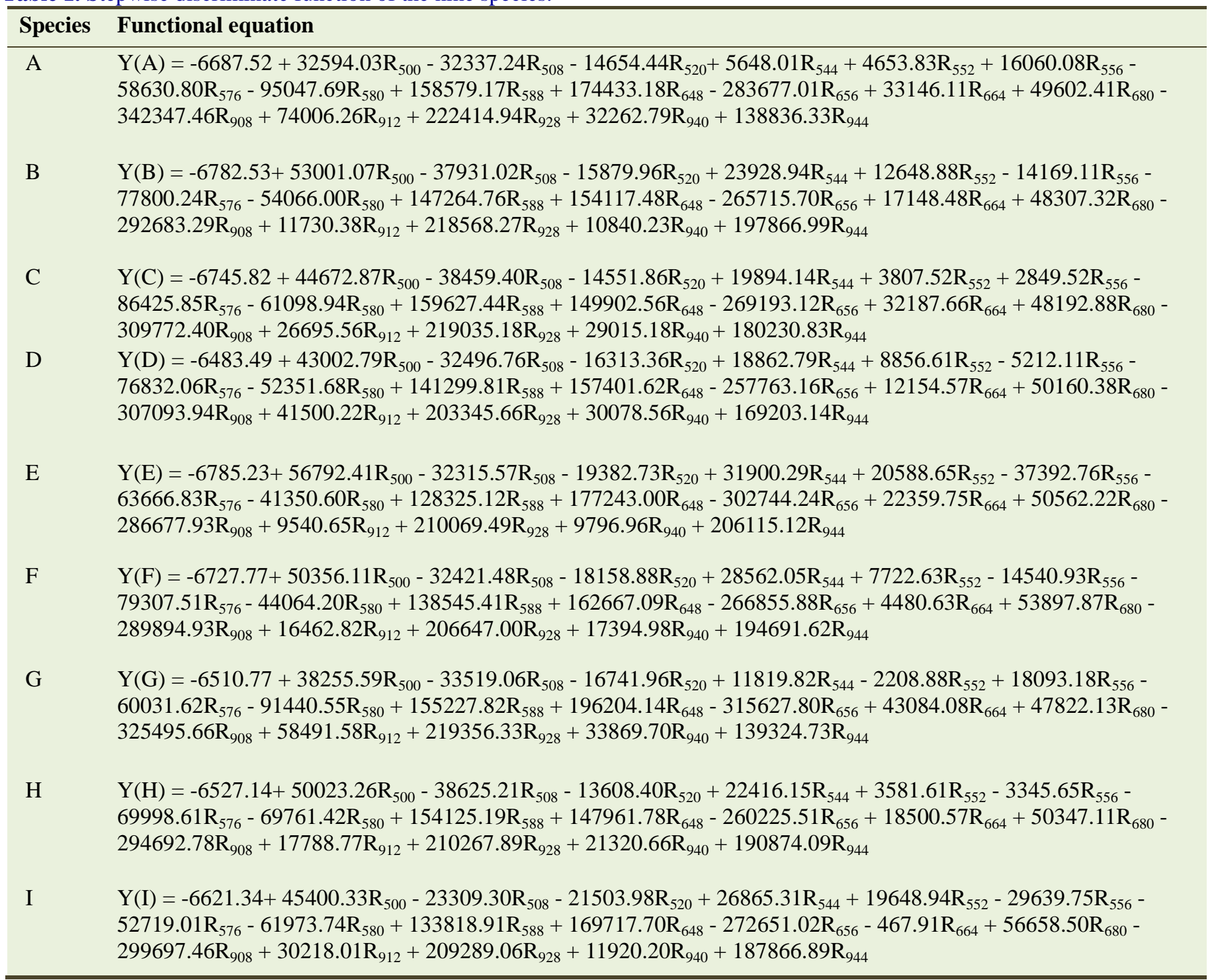

As the results shows in Table 2 below, when 18 band combinations were selected, the discrimination accuracies of the training samples and test samples were as high as $93.889 \%$ and $95.556 \%$, respectively. For determining whether the unique bands selected by discriminant analysis were the best band combinations, 6 unique bands were successively added to reconstruct the Bayes discriminant model. Through analysis, for a single species, when 6 unique bands were selected, the discrimination accuracies of the training samples and test samples were as high as $76 \%$ and $77 \%$, respectively; when the number of band combinations was increased to 12 , the accuracies of the two samples were up to $83 \%$ and $84 \%$, respectively. However, when the selected band combinations were less than 18 , them both accuracies decreased, indicating that this linear discriminant model established by 18 unique bands in this experiment was satisfactory. 
Table 2. Discrimination accuracy rate of model for training and prediction samples.

\begin{tabular}{|c|c|c|c|c|c|c|c|}
\hline \multirow{2}{*}{ Band combination } & \multirow{2}{*}{ Species } & \multicolumn{3}{|c|}{ Training samples } & \multicolumn{3}{|c|}{ Prediction samples } \\
\hline & & Number & Misjudgment & Accuracy\% & Number & Misjudgment & Accuracy\% \\
\hline \multirow[t]{9}{*}{6 band combination } & A & 20 & 2 & 90 & 10 & 1 & 90 \\
\hline & B & 20 & 8 & 60 & 10 & 0 & 100 \\
\hline & $\mathrm{C}$ & 20 & 10 & 50 & 10 & 5 & 50 \\
\hline & $\mathrm{D}$ & 20 & 5 & 75 & 10 & 4 & 60 \\
\hline & $\mathrm{E}$ & 20 & 4 & 80 & 10 & 4 & 60 \\
\hline & $\mathrm{F}$ & 20 & 4 & 80 & 10 & 1 & 90 \\
\hline & G & 20 & 2 & 90 & 10 & 0 & 100 \\
\hline & $\mathrm{H}$ & 20 & 4 & 80 & 10 & 4 & 60 \\
\hline & I & 20 & 4 & 80 & 10 & 1 & 90 \\
\hline \multirow[t]{9}{*}{12 band combination } & A & 20 & 0 & 100 & 10 & 0 & 100 \\
\hline & $\mathrm{B}$ & 20 & 2 & 80 & 10 & 0 & 100 \\
\hline & $\mathrm{C}$ & 20 & 0 & 100 & 10 & 0 & 100 \\
\hline & $\mathrm{D}$ & 20 & 0 & 100 & 10 & 1 & 90 \\
\hline & $\mathrm{E}$ & 20 & 1 & 95 & 10 & 0 & 100 \\
\hline & $\mathrm{F}$ & 20 & 3 & 85 & 10 & 2 & 80 \\
\hline & G & 20 & 0 & 100 & 10 & 1 & 90 \\
\hline & $\mathrm{H}$ & 20 & 11 & 45 & 10 & 3 & 70 \\
\hline & I & 20 & 12 & 40 & 10 & 7 & 30 \\
\hline \multirow[t]{9}{*}{18 band combination } & A & 20 & 0 & 100 & 10 & 0 & 100 \\
\hline & B & 20 & 1 & 95 & 10 & 0 & 100 \\
\hline & $\mathrm{C}$ & 20 & 0 & 100 & 10 & 0 & 100 \\
\hline & $\mathrm{D}$ & 20 & 0 & 100 & 10 & 1 & 90 \\
\hline & E & 20 & 0 & 100 & 10 & 0 & 100 \\
\hline & $\mathrm{F}$ & 20 & 0 & 100 & 10 & 0 & 100 \\
\hline & G & 20 & 0 & 100 & 10 & 0 & 100 \\
\hline & $\mathrm{H}$ & 20 & 8 & 60 & 10 & 2 & 80 \\
\hline & I & 20 & 2 & 90 & 10 & 1 & 90 \\
\hline
\end{tabular}

\section{Conclusion}

Spectral data for new leaves of one-year-old seedlings of 9 species of the genus Machilus Nees were measured with an instrument. The irrelevant information was removed, and stepwise discriminant analysis was utilized for screening the data. Eighteen unique bands were selected from 126 bands: $500 \mathrm{~nm}, 508 \mathrm{~nm}, 520 \mathrm{~nm}$, $544 \mathrm{~nm}, 552 \mathrm{~nm}, 556 \mathrm{~nm}, 576 \mathrm{~nm}, 580 \mathrm{~nm}, 588 \mathrm{~nm}, 648$ $\mathrm{nm}, 656 \mathrm{~nm}, 664 \mathrm{~nm}, 680 \mathrm{~nm}, 908 \mathrm{~nm}, 912 \mathrm{~nm}, 928 \mathrm{~nm}$, $940 \mathrm{~nm}, 944 \mathrm{~nm}$, and $956 \mathrm{~nm}$. These 18 unique bands were used to establish the discriminant analysis model for species of the genus Machilus Nees through the Bayesian discriminant method. The correct recognition rate of this model achieved up to $93.889 \%$ on training samples and $95.556 \%$ on test samples in 9 Machilus Nees species. This model reached higher discrimination precision, indicating that this technology could be applied in the identification and classification of Machilus Nees species.

Because of the difficulties in obtaining flowers and fruits of Machilus Nees plants, traditional classification methods using characteristics of flower and fruits for discrimination were not chosen in this study; in contrast, leaves, which were more easily obtained, were chosen for analysis. The leaves of Machilus Nees plants could be readily collected and could be analyzed directly after cleaning without complicated treatments. This method increases the efficiency, decreases the experimental 
error, causes very little damage to plants, and has small effect on the regular growth and development of plants; therefore, it is an ideal method for the identification of Machilus Nees plants.

\section{Conflict of interest statement}

Authors declare that they have no conflict of interest.

\section{Acknowledgement}

This work was supported by the Science and Technology Support Program in Hubei Province of P. R. China (2013BBB24), the Youth fund program in Yangtze University of P. R. China (2015cqn80), University Student Innovation Program in Yangtze, Hubei Province of P. R. China (20150118).

\section{References}

Chen, J.Q., Li, L., Li, J., 2009. Bayesian inference of nrDNA ITS sequences from Machilus (Lauraceae) and its systematic significance. Acta Bot. Yunnanica. 31(2), 117-126.

Chen, Z.G., Li, X., Fan, X.J., 2016. Method for the discrimination of the variety of potatoes with vis/nir spectroscopy. Spectrosc. Spect. Anal. 36(8), 24742478.

Li, J., Song, W.L., 2016. Water content model for strawberry leaves with spectral signature. J. Northeast Forestry Univ. 44(1), 72-74.

Li, X. W., Li, J., Huang, P. H., 2008. Lauraceae. In: Flora of China (Eds.: Wu, Z.Y., Raven, P.H., Hong, D.Y.). Vol. 7. Science Press, Beijing and Missouri Botanical Garden Press, St. Louis. pp.102-254.

Lin, H., Zang, Z., Liu, X.Y., 2011. Hyperspectral Remote Sensing of Forest Tree Species. China Forestry Press, Beijing. pp.110-119.

Lin, X.Z., 2007. Quantitative classification of plants of Machilus in Zhejiang Province. Sci. Silvae Sin.
43(11), 151-156.

Liu, Z.X., Fei, Y.J., 2011. Germplasm resources and conservation countermeasures on the Phoebe Nees and Machilus Nees species in China. J. Yangtze Univ. 8(5), 221-223.

Pontius, J., Hallett, R., Martin, M., 2005. Using AVIRIS to assess hemlock abundance and early decline in the Catskills, New York. Remote Sens. Environ. 97, 163-173.

Song, X.D., Jiang, H., Yu, S.Q., 2008. Relationship between chlorophyll concentrations and spectral reflectance feature of the typical evergreen hardwood species in subtropical region of China. Acta Ecol. Sin. 28(5), 5-10.

Tang, G.G., Xiang, Q.B., 1995. Pollen morphology of the family Lauraceae in China. Acta Phytotaxon. Sin. 33(2), 161-170.

Wang, Y. G., Wei, F. N., 2003. Comparative study of pollen morphology in Machilus and its related genus Phoebe under SEM. Guihaia. 22(1), 27-30.

Wei, F.N., Tang, S.C., 2006. A revision on several species of Machilus Nees (Lauraceae) from China and Vietnam. Guihaia. 26(4), 345-348.

Zhang, F., Xiong, Z., Kou, N., 2002. Airborne hyperspectral remote sensing image data is used for rice precise classification. J. Wuhan Univ. Technol. 24(10), 36-39.

Zhang, R., Xu, K. W., Zhang, L. S., 2014. Identification of five rosewood species by infrared spectrum characteristics. China Forestry Sci. Technol. 28(2), 95-99.

Zhong, Y., Xia, N. H., 2010. Leaf epidermal features of Machilus (Lauraceae) form China and their systematic significance. J. Trop. Subtrop. Bot. 18(2), 109-121.

Zhuang, L., Huang, Q., Xu, Y. H., 2014. Four kinds of Phoebe and Machilus wood infrared absorption spectrum identification. J. Fujian Forestry Sci. Technol. 41(4), 21-25.

\section{How to cite this article:}

Fei, Y., Xiao, B., Liao, X., Wen, S., Zhou, B., Pan, J., Hu, D., 2017. The identification method for Machilus Nees species based on visible-near infrared spectral analysis technology. Int. J. Curr. Res. Biosci. Plant Biol. 4(4), 1-6. doi: https://doi.org/10.20546/ijcrbp.2017.404.001 